"modest Utopia" would mean consuming $2 \cdot 3$ kilowatts each a year. That means something like a sevenfold increase for the poor, which combined with a doubling of their numbers by 2050 would mean a 14-fold increase in their energy consumption. Yet, said Lord Porter, we have enough oil and gas to last something like 50 years at current rates of consumption and energy from nuclear fusion will not be widely available for half a century even if the reaction is achieved in the laboratory tomorrow. Furthermore, the rise in concentrations of carbon dioxide resulting from energy consumption is the cause of global warming.

Lord Porter was not in apocalyptic mood at the meeting, but he did make clear-as did others-that to survive we need to look at radical changes in our values and our lives. Conservation will have only a minuscule effect on energy consumption. In both the rich and poor worlds we must rethink how we transport ourselves, what we eat (Californian steak demands huge inputs of water, energy, and land), how many children we have, and how we live. The British, for instance, may currently have more public debate on infertility than fertility, but a country that contained 30 million rather than 56 million people would be less environmentally ravaged and make a smaller contribution to global destruction.

RICHARD SMITH

Editor

BMF, London WC1H 9JR

\title{
Pre-employment chest radiography and NHS staff
}

\section{Not needed for asymptomatic people with strongly positive tuberculin skin reactions}

Most people who have worked in the NHS will remember the ritual pre-employment chest radiograph. The Department of Health has endorsed this practice, ${ }^{1}$ which has continued in most districts until recently. Its main rationale is to detect cases of pulmonary tuberculosis. A review of recent evidence suggests, however, that routine pre-employment chest radiography of NHS staff is not an effective or efficient way of doing this.

In two series of routine pre-employment radiographs in the late 1980s abnormalities were rare, and no evidence of tuberculosis was found in nearly 3000 films. The authors recommended restricting pre-employment radiography to those people with strongly positive tuberculin skin tests. ${ }^{23}$ In 1990 a subcommittee of the joint tuberculosis committee of the British Thoracic Society recommended a pre-employment chest radiograph for NHS employees with a grade 3 or 4 Heaf reaction and for those with a grade 2 reaction without a BCG scar, taking such Heaf reactions as evidence of infection with tuberculosis. ${ }^{4}$ The aim was to reduce the number of preemployment chest radiographs.

But strongly positive tuberculin skin reactions are common among NHS employees with and without BCG scarss: NHS occupational physicians in London and Manchester estimated that perhaps half their new employees would require a chest radiograph using the British Thoracic Society's criteria. ${ }^{67}$ Given the very large clinical workforce of the NHS with its high turnover rate, the society's criteria require that each year thousands of new employees have pre-employment radiography. Is this justifiable? Are NHS employees with strongly positive skin tests really at an appreciable risk of having tuberculosis?

A case-referent study from London of employees who had routinely had pre-employment radiography found that abnormalities were rare ( 68 out of 5000 ). No excess of positive skin tests was found among those with abnormal radiographs compared with control subjects with normal radiographs. ${ }^{78} \mathrm{~A}$ recent study in the west midlands reviewed the working of the British Thoracic Society's recommendations during 1990-2. Among 8475 new staff, about $6 \%$ had grade 3 or 4 Heaf reactions, and therefore had radiography. There was no evidence of active tuberculosis on any of the films and only 3\% of them were abnormal in any way. A prospective study from London published in the BMJ last month confirmed that strongly positive skin tests in new hospital employees are common, whether or not a.BCG scar is present. ${ }^{10}$ On the basis of the British Thoracic Society's guidelines, over a third of the
640 new employees during one year had chest radiography; no cases of tuberculosis were detected.

These recent studies indicate that routine pre-employment chest radiography for people with strongly positive tuberculin skin reactions are of unproved value and should be stopped. So when is pre-employment chest radiography indicated? Nearly all cases of active pulmonary tuberculosis are symptomatic. ${ }^{11}$ A review of cases of tuberculosis in NHS staff found that most presented with symptoms, rather than being detected on routine annual radiography. ${ }^{12}$ Finding cases of active tuberculosis on routine pre-employment radiography among people not admitting to symptoms on direct questioning is very unlikely. Pre-employment health screening should include inquiries about symptoms suggestive of pulmonary tuberculosis, including persistent cough, unexplained weight loss, malaise, and night sweats. Radiographs should be reserved for symptomatic people. This will save time and money and avoid unnecessary irradiation of healthy people.

ANNE COCKCROFT

Occupational Health Unit, Consultant

Royal Free Hospital,

London NW3 2QG

1 Department of Health and Social Security. Health service management: control of tuberculosis in NHS employees. London: DHSS, 1978. (HC(78)3.)

2 Jachuck SJ, Bound CL, Jones CE, Bryson M. Is a pre-employment chest radiography necessary for NHS employees? BMF 1988;296:1187-8.

Krarup KC, Scarisbrick DA. Control of tuberculosis in health service workers: the role of the chest radiograph. F Soc Occup Med 1989;39:128-30.

4 Subcommittee of the Joint Tuberculosis Committee of the British Thoracic Society. Control and prevention of tuberculosis in Britain: and updated code of practice. BMF 1990;300:995-9.

5 Cockcroft A, Chapman S, Insall C, Soper P, Kennard Y, Hollis C. Tuberculin reactivity in new employees in a London Health district. Thorax 1988;43:834.

6 Gatley MS. Tuberculosis in Britain. BMF 1990;300:1339.

6 Gatley MS. Tuberculosis in Britain. BMF 1990;300:1339.

7 Cockcroft A, Chaturvedi N, Waldron HA. Tuberculosis in Britain. BMf 1990;300:1723-4. $\mathrm{x}$-rays? Occup Med 1992;42:179-182.

9 Burge A, Kumar S, Skinner C. Control of tuberculosis in NHS staff: west midlands 1990-92. Thorax 1993;48:463.

10 Madan I. Pre-employment chest $x$-rays for health service staff: who needs them? $B M J$ 1993;306:1041-2.

11 Howell F, Kelly P, Clancy L. Pulmonary tuberculosis in the Republic of Ireland: an epidemiological profile from a single unit. Respir Med 1990;84:111-7.

12 Lunn JA, Mayho V. Incidence of pulmonary tuberculosis by occupation of hospital employees in the national health service in England and Wales 1980-84. I Soc Occup Med 1989;39:30-2.

\section{Correction}

\section{Screening for ovarian cancer}

Owing to an author's error, the cost per case of potentially curable ovarian cancer was reported by Maurice J Webb (17 April, p 1015) as $\$ 1 \mathrm{~m}$. The correct figure is $\$ 44000$. 